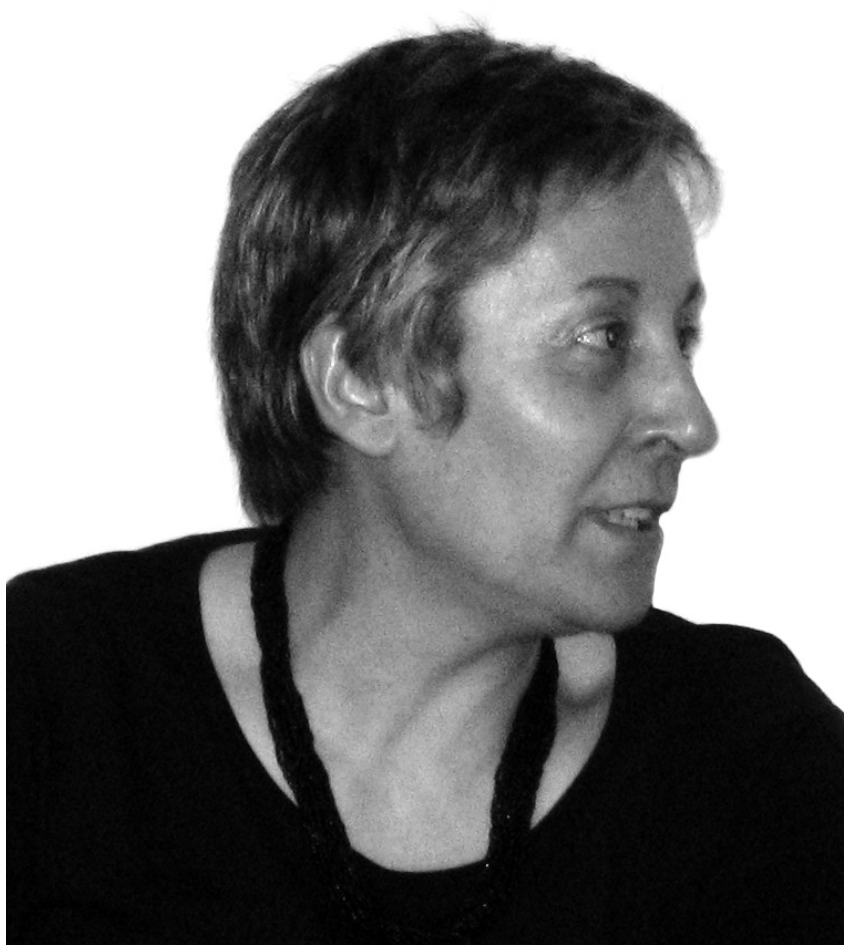

\title{
Otília da Conceição Pires Martins
}

Dialogia Como especialista no estudo das representações de Portugal nas literaturas estrangeiras e do estrangeiro na literatura portuguesa, gostaríamos de saber da senhora qual é a real situação, atualmente, das literaturas de expressão portuguesa no mundo?

Professora Associada da Universidade de Aveiro - Portugal;

Diretora do Curso de Mestrado em Tradução Especializada (Universidade de Aveiro); Presidente do Conselho Fiscal da Associação Portuguesa de Literatura Comparada; Autora de obras de crítica literária, como L'oeuvre de Julien Green: une poétique du mal. Dualité et déchirure dans l'univers greenien (Lisboa: Colibri, 2008). omartins@ua.pt
OM: A real situação não é demasiado encorajadora. As pessoas não se interessam por coisa abstractas como "as literaturas de expressão portuguesa". Em geral, as pessoas - refiro-me ao vulgo, não aos especialistas - demonstram interesse por um autor apelativo, e não pelo conjunto cultural ou literário em que ele se insere. Por exemplo, os que gostam de ler os Cem anos de solidão, do colombiano Garcia Marques, não conhecem nem querem saber da literatura na Colômbia. Lá fora, lê-se o moçambicano Mia Couto, mas isso não leva as pessoas automaticamente a se interessar pelos também moçambicanos Paulina Chiziane, Albino Magaia ou Juvenal Bucuane ou mesmo Ungulani Ba Ka Khosa. Disso, aliás, se queixam eles, mas sem razão.

Dialogia - Os críticos costumam dizer que a literatura portuguesa é mais lida no Brasil do que a brasileira em Portugal. Na sua opinião, isso é, de fato, uma realidade? Portugal e Brasil têm conhecimento, por exemplo, do que se publica, atualmente, nos dois países?

OM: Não sei, de fonte segura, se a literatura portuguesa é mais ou menos lida do que a brasileira em Portugal. Mas sei, 
isso sim, que a literatura brasileira não é lida em Portugal na proporção da sua riqueza. 0 próprio Machado de Assis não é tão conhecido quanto devia. Em Portugal, o escritor brasileiro de maior fortuna editorial continua a ser Jorge Amado, que está longe de ter, a meu ver, a importância literária de um Guimarães Rosa, de um Graciliano Ramos, de um Érico Veríssimo da última fase etc. $\mathrm{Na}$ poesia, são razoavelmente conhecidos, em Portugal, Manuel Bandeira, Carlos Drummond de Andrade, João Cabral de Melo Neto, Vinícius de Morais e pouco mais. Refiro-me ao público em geral e não aos happy few. Que isso não se torne demasiadamente estranho, mas bem mais perto de nós - e nada inacessível à leitura por portugueses temos, ao nosso lado, a literatura espanhola, com autênticos gigantes a representá-la e que pouquíssimos portugueses conhecem. Os textos seminais de Ortega y Gasset, de Unamuno, de Pio Baroja, de Valle Inclán, de Azorin etc. são desconhecidos de um grande número de portugueses ditos "cultos".

Dialogia: No Brasil, sobretudo nos anos 1980 e 1990, os estudos de recepção, no comparatismo literário, estiveram bastante em voga nas universidades, procurando observar, por exemplo, a recepção na literatura brasileira tanto de autores portugueses (como Eça de Queirós, Fernando Pessoa, Camilo Castelo Branco, Camões) quanto franceses (Victor Hugo, Baudelaire, Musset) e ingleses (Shakespeare, Byron). Esta é uma tendência que ainda se mantém nos estudos literários de um modo geral? Particularmente em Portugal, como está a situação dos estudos comparatistas atualmente?
OM: Os estudos comparatistas continuam vivos no espaço português, onde nomes, tais como os de Álvaro Manuel Machado e Maria Alzira Seixo são referências incontornáveis. É, contudo, verdade que a pergunta "a literatura comparada ainda existe?" sugere uma alteração de paradigma nos últimos anos. Para além da influência deste ou daquele autor ou do estudo da recepção de obras de autores estrangeiros em Portugal, surgem outros aspectos. Com efeito, o estudo das imagens e da representação do estrangeiro teve um forte incremento nas últimas décadas, no âmbito da investigação em literatura comparada, permitindo a emergência de uma área de reflexão designada por imagologia, cujo início teve como marco cronológico a década de 1940 do século XX. A imagologia configura um domínio que tem despertado uma atenção crescente por parte dos investigadores, estabelecendo ligações evidentes com outros domínios emergentes dos estudos literários e da literatura comparada, tais como a moderna área dos Cultural Studies, de tradição anglo-saxónica, sem esquecer os estudos de recepção e tradução ou ainda a mitocrítica. A consciência de que a época actual é dominada pelo diálogo entre culturas justifica, em larga medida, o interesse que o estudo das imagens do estrangeiro tem despertado no âmbito das ciências humanas.

Dialogia: Com a voga dos estudos culturais, do advento da Pós-Modernidade, das abordagens multiculturalistas da literatura, a teoria literária parece estar passando por um amplo processo de revisão ou, pelo menos, sofrendo transformações consideráveis em seu escopo teórico e metodológico. Qual é, na opinião da senhora, o papel reservado à teoria literária no contexto contemporâneo, em que 
a globalização parece ser o conceito mais recorrente? Como se configuram atualmente, em Portugal, os estudos literários dentro e fora da universidade? como ela se apropria das formas literárias européias e transforma-as, conferindolhes novo viço. Os termos do sistema hierárquico anterior invertem-se no processo e o texto da cultura dominada acaba por configurar-se como o mais rico dos dois.

OM: Confesso não entender muito bem o alcance desta pergunta. $\mathrm{O}$ que a teoria da literatura tem de mais permanentemente válido (e é bem menos do que se supõe...) não me parece poder ser afectado, de modo substancial, pela chamada globalização. E, no multiculturalismo, reina, a meu ver, muita confusão e muito wishful thinking.

Dialogia: $\quad$ Eduardo

\section{"A imagologia configura um domínio que tem despertado uma atenção crescente por parte dos investigadores, estabelecendo ligações evidentes com outros domínios emergentes dos estudos literários e [...]"}

(COUTINHO, 2003, p. 21).

Como fica a questão - num momento em que põe sob suspeita o conceito de "cânone" e se combate a idéia de "etnocentrismo" - dos juízos de valores no trabalho comparatista? A Europa continua sendo um modelo exemplar de produção estética para o mundo ou houve uma disseminação desse papel por outros continentes?

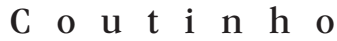

(Universidade

Federal do Rio de Janeiro), em seu livro Literatura comparada na América Latina (2003), apoiando-se no conceito de "transculturação”, de Ángel Rama, afirma que

[...] o que passa a prevalecer na leitura comparatista não é mais a relação de semelhança ou continuidade, sempre desvantajosa para o texto segundo, mas o elemento de diferenciação que este último introduz no diálogo intertextual estabelecido com o primeiro [...] Os critérios, até então inquestionáveis de originalidade e anterioridade, são lançados por terra e o valor da contribuição latino-americana passa a residir exatamente na maneira
OM: O problema de quem influencia quem ou de quem enriquece, quem fica mais pobre do que aquele que enriqueceu à sua custa - parece-me um pouco estéril. E tanto me parece improcedente dizer que a literatura latino-americana é inferior a europeia pelo fato de os literatos latinos, usarem-na como referência quando afirmar que "os termos do sistema hierárquico anterior invertem-se no processo e o texto da cultura dominada acaba por configurar-se como o mais rico dos dois". Isto épolitical correctness, no seu pior aspecto. As literaturas que vieram depois apropriam-se, nas outras, daquilo que lhes convém e, com isso, fazem "outra coisa". Para o fazerem, algo lhe "acrescentam". Por outro lado, "deixam de aproveitar" aquilo que lhes não interessa, mas que não é pobreza e continua a "enriquecer" as li- 
teraturas originárias. Algo se ganha e algo se perde ou se deixa de ganhar. Qual é o balanço final? E será de muito interesse qualquer critério contabilístico? As literaturas europeias e as fontes que elas foram beber são "diferentes" umas das outras. Haverá margem para uma hierarquia?

Dialogia: Saindo um pouco do universo das literaturas brasileira e portuguesa, qual é atualmente, na opinião da senhora, a importância das literaturas africanas de expressão portuguesa no mundo ocidental? Como se dá a relação dessas literaturas, que até há pouco tempo encontravam-se na condição de literaturas coloniais, com Portugal?

OM: A importância é pequena. No que diz respeito à relação com Portugal, a resposta não é muito encorajadora. Há nas universidades portuguesas uma dimensão muito reduzida de estudos de literaturas africanas de língua portuguesa. O que é estranho e lastimável, embora pouco tenha de novo. Há escritores, como Mia Couto, que são muito lidos e muito estudados, ou como Pepetela, que o é razoavelmente. Craveirinha é conhecido de nome, mas duvido que seja muito lido, apesar do Prémio Camões, que lhe foi concedido algo paternalisticamente. E o que mais se cita dele não é, nem pouco mais ou menos, o melhor que escreveu. Este relativo desinteresse já existia em relação às literaturas escritas em Angola ou Moçambique, no tempo colonial (convindo, desde logo, notar que muita dessa literatura - quase sempre a melhor - escrita no tempo colonial não era uma literatura "colonialista": Craveirinha, Luis Bernardo Honwana, Reinaldo Ferreira, Castro Soromenho, Rui Knopfli,
Glória de Sant’Ana, João Pedro Grabato Dias eram notáveis escritores não colonialistas a escreverem num tempo colonial). No tempo colonial, dizia eu, os melhores escritores que produziam suas obras no chamado "ultramar" (colónias) tinham pouca ou nenhuma visibilidade na chamada "metrópole". Quando se tratava de poetas geniais como Grabato Dias, a desatenção era simplesmente escandalosa. Mas era um facto. A desatenção, repito, não é de hoje nem de ontem: é de sempre.

Dialogia: O fato de autores africanos lusófonos estarem sendo cada vez mais traduzidos para as línguas do mundo ocidental significa, de algum modo, que as literaturas, até então tidas como periféricas, estão ocupando espaços deixados pelas literaturas canônicas? Deve-se falar, nesse momento, em conflito ou em conciliação de interesses quando se pensa na literatura produzida nos continentes europeu, africano e latino-americano?

OM: Acho grande optimismo falar de os "autores africanos estarem a ser cada vez mais traduzidos para as línguas do mundo ocidental". Uma andorinha não faz a primavera. Mia Couto não é toda a literatura africana de língua portuguesa. Por outro lado, as grandes literaturas canónicas não deixam espaços a serem preenchidos por outras menos canónicas, desde que produzam escritores suficientemente apelativos para que os desejem ver traduzidos.

Entrevista concedida por e-mail ao prof. Maurício Pedro da Silva, editor científico de Dialogia. 